Article

\title{
Diaphragm-Free Fiber-Optic Fabry-Perot Interferometric Gas Pressure Sensor for High Temperature Application
}

\author{
Hao Liang, Pinggang Jia * (D), Jia Liu, Guocheng Fang, Zhe Li, Yingping Hong, Ting Liang and \\ Jijun Xiong
}

Science and Technology on Electronic Test and Measurement Laboratory, North University of China, Taiyuan 030051, China; lianghao_nuc@163.com (H.L.); liujianuc@163.com (J.L.); 18734915430@163.com (G.F.); lizhenuc@163.com (Z.L.); hongyingping_2014@163.com (Y.H.); liangtingnuc@163.com (T.L.); xiongjijun@nuc.edu.cn (J.X.)

* Correspondence: pgjia@nuc.edu.cn; Tel.: +86-351-3925-088

Received: 8 February 2018; Accepted: 27 March 2018; Published: 28 March 2018

\begin{abstract}
A diaphragm-free fiber-optic Fabry-Perot (FP) interferometric gas pressure sensor is designed and experimentally verified in this paper. The FP cavity was fabricated by inserting a well-cut fiber Bragg grating (FBG) and hollow silica tube (HST) from both sides into a silica casing. The FP cavity length between the ends of the SMF and HST changes with the gas density. Using temperature decoupling method to improve the accuracy of the pressure sensor in high temperature environments. An experimental system for measuring the pressure under different temperatures was established to verify the performance of the sensor. The pressure sensitivity of the FP gas pressure sensor is $4.28 \mathrm{~nm} / \mathrm{MPa}$ with a high linear pressure response over the range of 0.1-0.7 $\mathrm{MPa}$, and the temperature sensitivity is $14.8 \mathrm{pm} /{ }^{\circ} \mathrm{C}$ under the range of $20-800{ }^{\circ} \mathrm{C}$. The sensor has less than $1.5 \%$ non-linearity at different temperatures by using temperature decoupling method. The simple fabrication and low-cost will help sensor to maintain the excellent features required by pressure measurement in high temperature applications.
\end{abstract}

Keywords: fiber-optic; Fabry-Perot; FBG; gas pressure sensor; high temperature

\section{Introduction}

Compared with conventional pressure sensors, fiber-optic pressure sensors are widely used for pressure measurement of gases under high temperature because of their advantages of resistance to harsh environments, immunity to electromagnetic interference, small size and high sensitivity [1-4]. Fiber optic pressure sensors are mainly based on the Mach-Zehnder interferometer, Michelson interferometer, and FP interferometer techniques [5-7]. Compared to other types, the FP interferometric pressure sensor, with its advantages of high sensitivity, small size and compactness, had been widely used for measuring pressure [8]. Researchers have paid much attention to the diaphragm-based fiber-optic Fabry-Perot pressure sensor. Melissinaki et al. [9] proposed a Fabry-Perot micro-optical sensing resonator fabricated by direct laser writing on the end face of a standard telecom fiber that was demonstrated for tracing the vapors of common organic solvents. Poeggel et al. [10] reported an inexpensive all-silica fiber-optic extrinsic Fabry-Perot interferometric pressure sensor with a fiber Bragg grating added in proximity of the sensing tip, which could compensate temperature variations with $0.5^{\circ} \mathrm{C}$ accuracy. Wang et al. [11] presented a fiber Fabry-Perot interferometer and a fiber Bragg grating-based pressure and temperature multiplexed sensor system with pressure and temperature measurement accuracy of $0.03 \mathrm{Mpa}$ and $0.5{ }^{\circ} \mathrm{C}$ in the temperature variation range between $18{ }^{\circ} \mathrm{C}$ 
and $300^{\circ} \mathrm{C}$. Duraibabu et al. [12] proposed a novel miniature pressure sensor combined with a FBG for the ocean environment with a depth accuracy of about $0.01-0.03 \mathrm{~m}$ and resolution of $\sim 0.5 \mathrm{~cm}$. However, considering that diaphragm-based pressure sensors will suffer plastic deformation under high temperature, diaphragm-free sensors can work at higher temperatures and have a wide pressure measurement range. For instance, Villatoro et al. [13] reported an in-reflection photonic crystal fiber interferometer which exhibited high sensitivity to different volatile organic compounds. Ran et al. [14] demonstrated a diaphragm-free pressure sensor which realized pressure measurements from room temperature to $700{ }^{\circ} \mathrm{C}$ made by splicing a SMF to a photonic crystal fiber (PCF) with a hole fabricated by a 157-nm laser at the end of the PCF. Ferreira et al. [15] proposed an FP interferometric sensor with a sensitivity of $0.82 \mathrm{~nm} / \mathrm{MPa}$ for pressure measurement manufactured by splicing a part of HCR-PCF to a standard SMF. Xu et al. [16] fabricated a micro-cavity fiber Fabry-Perot interferometer with a high gas sensitivity of $4.15 \mathrm{~nm} / \mathrm{MPa}$ by splicing a tiny segment of a main-capillary with a feeding-capillary on one end and a SMF on the other. The measurement results of the above sensors are easily affected by the thermal expansion and the elastic modulus change of the material when applied in a high temperature environment which seriously affects the sensor accuracy. Moreover, these sensors generally have the common disadvantages of a complicated manufacturing process, high cost and the fact their working temperature is not high enough, etc.

This paper proposes a diaphragm-free fiber-optic Fabry-Perot (FP) interferometric gas pressure sensor. According to the principle whereby the gas density varies with the pressure change, pressure can be measured from room temperature to $800{ }^{\circ} \mathrm{C}$. The sensor material is silica which has a very low temperature drift. In addition, a temperature compensation structure is designed in the sensor to offset the effect of the thermal expansion between the structures on the pressure measurement of the sensor, which further reduces the temperature drift of the sensor. The FBG which is inscribed by a femtosecond laser [17] is used for temperature decoupling. A temperature decoupling method was proposed to improve the accuracy of the sensor in high temperature applications. The sensor proposed in this paper would not suffer the problem of the plastic deformation which provides a method of pressure measurement at high temperature. The sensor has the advantages of simple structure, low cost, simple fabrication, low temperature coefficient, high accuracy and it can work stably at a high temperature of $800{ }^{\circ} \mathrm{C}$ and moreover, hopefully be used at a higher temperature.

\section{Operating Principle}

The structure of the fiber-optic FP gas pressure sensor is shown in Figure 1. The sensor is composed of a SMF with FBG and a HST which are integrated into a silica casing from both ends. The SMF and HST is fixed and connected by silica casing and the FP cavity is formed between the ends of the SMF $\left(S_{1}\right)$ and the HST $\left(\mathrm{S}_{2}\right)$, as shown in Figure 1. The hole of the HST provides easy access of the outside gas.

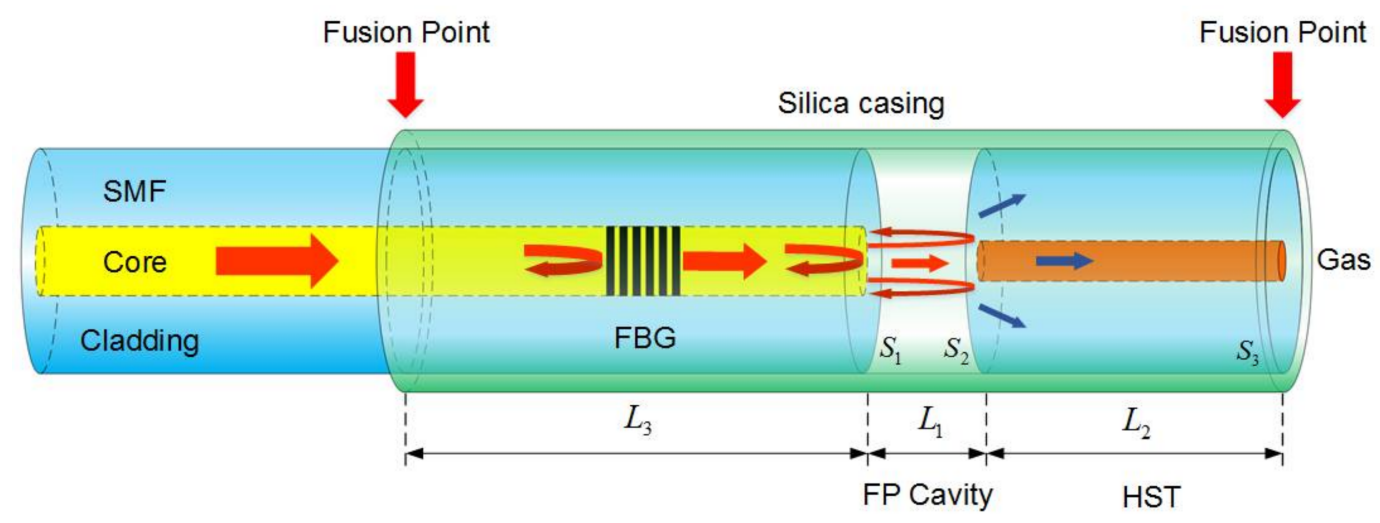

Figure 1. Schematic of the fiber-optic FP gas pressure sensor for high temperature. 


\subsection{Optical Interference Principle}

When the incident light travels along the SMF into the sensor, the light is partially reflected by the FBG, $S_{1}, S_{2}$ and the outer surface of the HST $\left(S_{3}\right)$, as shown in Figure 1 . The incident light with intensity $I_{\text {in }}$ initially reflected at FBG, then the transmitted light is reflected at the two reflecting surfaces $S_{1}, S_{2}$ of the FP and $S_{3}$, the three reflected lights interfere with each other and return to the FBG. However, the light reflected by $S_{3}$ forms a small period fringe with a greater contrast which has an impact on the interference spectrum. Therefore, in order to get a better interference spectrum, etching $\mathrm{S}_{3}$ with $\mathrm{HF}$ acid, the light reflected at $S_{3}$ cannot enter into the SMF which can be neglected. So the light returned to the FBG is the interference light of the FP. The intensity of the output light $I_{\text {out }}$ can be defined as [18]:

$$
I_{\text {out }}=I_{\text {in }} \cdot\left[f_{F B G}+\left(1-f_{F B G}\right)^{2} \cdot f_{F P}\right],
$$

where $f_{F B G}$ and $f_{F P}$ are the reflection coefficients of FBG and FP cavity. They are defined as [18]:

$$
\begin{aligned}
f_{F B G} & =R_{1} \cdot \exp \left[-\left(\lambda-\lambda_{F B G}\right)^{2} / w^{2}\right], \\
f_{F P} & =2 R_{2} \cdot[1+\cos (4 \pi L / \lambda+\pi)],
\end{aligned}
$$

where $R_{1}$ is the FBG peak reflectivity, $\lambda_{F B G}$ is the FBG center wavelength, $w$ is the bandwidth of the FBG reflection peak, $R_{2}$ is the reflectivity of the fiber end, and $L$ is the length of the FP cavity:

$$
L=\frac{\lambda_{1} \cdot \lambda_{2}}{2\left(\lambda_{2}-\lambda_{1}\right)}
$$

where $\lambda_{1}, \lambda_{2}$ are the wavelength of adjacent peak-peak (or valley-valley).

An interference spectrum simulation of the proposed sensor is shown in Figure 2. In the simulation, the FBG center wavelength is $\lambda_{F B G}=1575 \mathrm{~nm}$ with peak reflectivity of $65 \%$, the bandwidth of the FBG reflection peak is set as $\mathrm{w}=0.5 \mathrm{~nm}$, and the length of FP cavity is set as $\mathrm{L}=90 \mu \mathrm{m}$. The incident light has spectrum range of $1510-1590 \mathrm{~nm}$. From Figure 2, it can be seen that the temperature monitoring point corresponding to the center wavelength of the FBG $\left(\lambda_{F B G}\right)$, according to the temperature sensing principle of FBG, the temperature can be calculated by the center wavelength shift of the FBG and finally achieve the purpose of temperature decoupling.

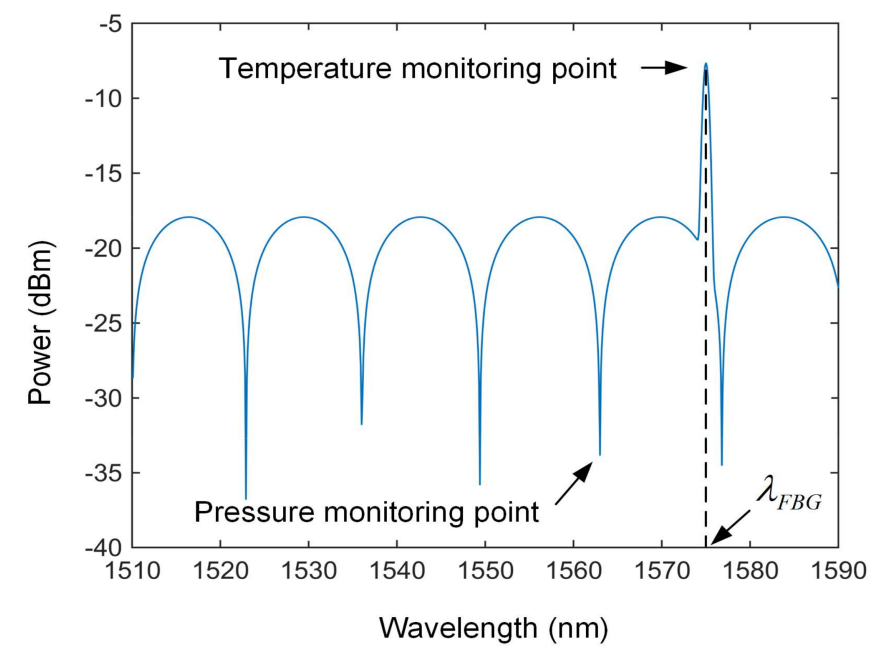

Figure 2. Interference spectrum simulation of the fiber-optic FP gas pressure sensor. 


\subsection{Temperature Decoupling Principle}

At present, pressure sensors have common problems of material thermal expansion and the change of elastic modulus in high temperature environments, which directly affect the temperature drift and sensitivity of the pressure sensor. This obviously limits the applications of these pressure sensors.

In order to eliminate the effect of thermal expansion between the different materials under high temperature, a temperature compensation structure is designed in this paper. The distance between $S_{1}$ and the left fusion point is $L_{3}$, and the distance between $S_{1}$ and $S_{2}$ is $L_{1}$, as shown in Figure 1. In our previous research [19], the experimental results showed that by setting the ratio of $L_{3}$ and $L_{1}$ as 9:1, the effects on the sensor due to the different coefficients of thermal expansion between the SMF and the silica casing can be eliminated. The temperature compensation structure greatly reduces the zero drift in high temperature environments.

For the problem of the change of elastic modulus under high temperature, a temperature decoupling method is presented in this paper. Initially, fitting the FBG center wavelength at different temperatures, the temperature of the sensor can be calculated by the center FBG wavelength. Next, the sensor is calibrated at a specific temperature, fitting the sensitivity to get the relationship between the temperature and sensitivity. Finally, the gas pressure can be calculated by the correspondence of the FBG center wavelength, sensitivity and temperature. Through the temperature decoupling method, the accuracy of the fiber-optic FP gas pressure sensor can be significantly improved in high temperature environments.

\section{Sensor Fabrication}

A microscopic image of the sensor is shown in Figure 3. The FBG peak reflectivity, bandwidth and center wavelength are $65 \%, 0.5$ and $1575 \mathrm{~nm}$, respectively. The distance between the end face of the SMF and the HST, and the inner diameter of the HST have a great influence on the spectrum. The contrast of the interference spectrum decreases as the inner diameter increases. After comprehensive consideration, we chose the HST with an inner diameter of $5 \mu \mathrm{m}$. The specifications of the SMF, silica casing and HST of the sensor are listed in Table 1. Due to the protection of the silica casing, the two reflection surfaces of $S_{1}$ and $S_{2}$ were kept in parallel. The fusion points are at both ends of the casing, which can better protect the two reflection surfaces from being damaged. At a certain temperature, the silica casing prevents the HST from collapsing due to overheating. By controlling the insertion length of the HST, the length of the FP cavity can be flexibly controlled.

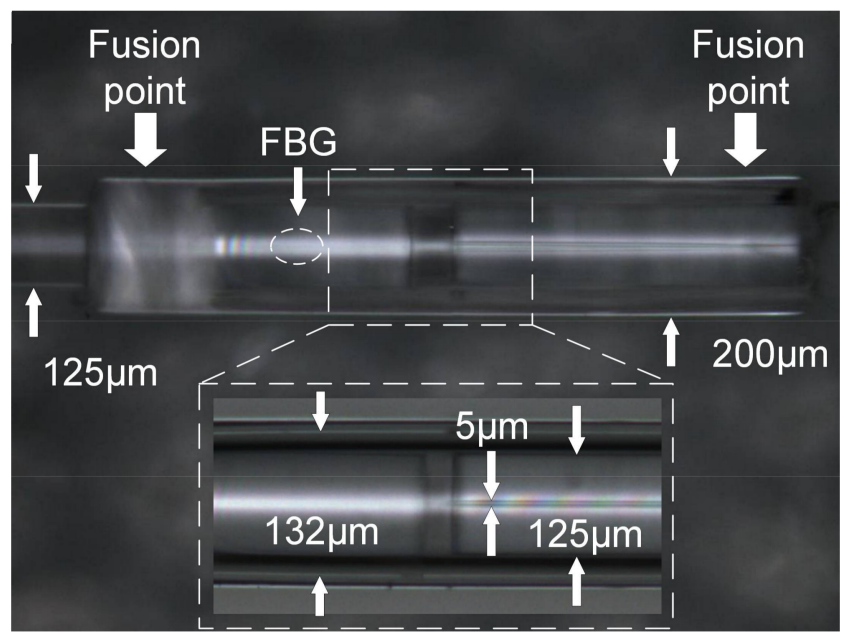

Figure 3. Microscopic image of the fiber-optic FP gas pressure sensor. 
Table 1. The specs of parts used in the sensor.

\begin{tabular}{cccc}
\hline Part Name & Type & Inner Diameters (um) & Outer Diameters (um) \\
\hline SMF & $\begin{array}{c}\text { G652D, Yangtze Optical Fiber and Cable } \\
\text { Co., Ltd., Wuhan, China }\end{array}$ & 9 & 125 \\
\hline Silica casing & $\begin{array}{c}\text { YN132200, Yongnian Ruipu Chromatogram } \\
\text { Equipment Co., Ltd., Hebei, China }\end{array}$ & 132 & 200 \\
\hline HST & $\begin{array}{c}\text { YN005125, Yongnian Ruipu Chromatogram } \\
\text { Equipment Co., Ltd. }\end{array}$ & 5 & 125 \\
\hline
\end{tabular}

Figure 4 illustrates the fabrication process of the sensor. The sensor was fabricated as follows. Firstly, the SMF and the silica casing well were cleaved with a fiber cleaver, as shown in Figure 4a. Inserting the SMF into the silica casing by the manual fusion procedure of the splicer (FITEL, S183 version 2, Tokyo, Japan). Discharged 1-2 times at the left fusion point, as shown in Figure $4 \mathrm{~b}$. The parameters of the splicer were set as A. The silica casing was cleaved at a suitable distance from the end of the SMF with the fiber cleaver under a microscope, as shown in Figure 4c. Next, cleaved the HST well with the fiber cleaver and inserted the HST from the opposite end of the silica casing by the manual fusion procedure of the splicer, as shown in Figure 4d. Kept a suitable distance with the end of the SMF to form the FP cavity. Discharged 1-2 times at the right fusion point, as shown in Figure 4e. The parameters of the splicer were set as B. Finally, the excess of the HST was cleaved off under a microscope, as shown in Figure 4f. The fusion parameters are shown in the Table 2.

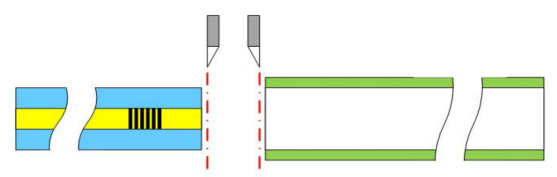

(a)

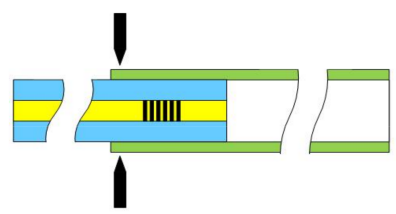

(b)

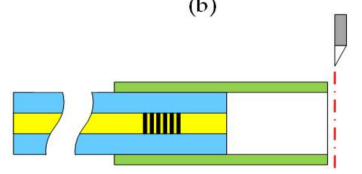

(c)

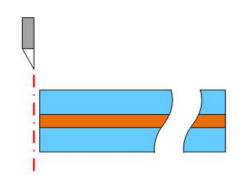

(d)

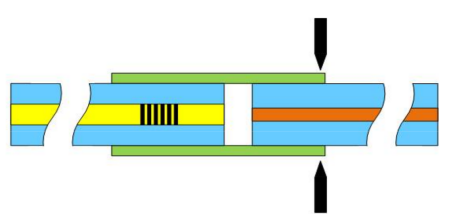

(e)

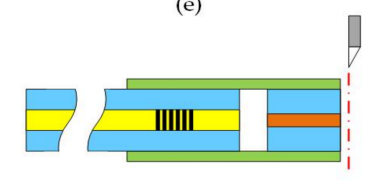

(f)

Figure 4. The schematic of the fabrication process. (a) Well-cleaved the SMF and silica casing. (b) Fusing the SMF and silica casing together at the end of the silica casing. (c) Cleaved the silica casing. (d) Well-cleaved the HST. (e) Fusing the silica casing and HST together at the other end of the silica casing. (f) Cleaved the excess of the HST.

Table 2. Fusion parameters.

\begin{tabular}{ccccc}
\hline & Clean Intensity & Clean Time & Fusion Intensity & Fusion Time \\
\hline A & 200 units & $250 \mathrm{~ms}$ & 100 units & $600 \mathrm{~ms}$ \\
B & 120 units & $180 \mathrm{~ms}$ & 100 units & $800 \mathrm{~ms}$ \\
\hline
\end{tabular}

The incident light reflected by the FBG, $S_{1}, S_{2}$ and $S_{3}$ form an interference spectrum, which is shown in black in Figure 5. From the result, in order to get the interference spectrum with less influence, etched the $\mathrm{S}_{3}$ with hydrofluoric acid, the interference spectrum is shown in red in Figure 5. The wave 
superimposed on the interference spectrum is due to the tiny distance between the $S_{1}$ and the FBG when cleaved under the microscope. The results well agreed with the simulation as shown in Figure 2.

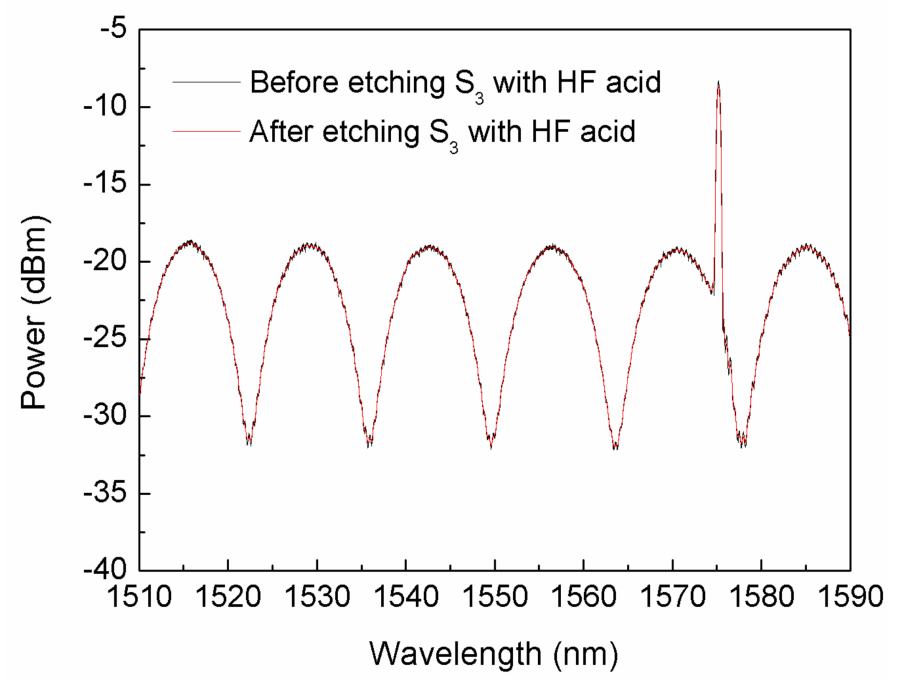

Figure 5. Interference spectrum of the fiber-optic FP gas pressure sensor with FP interferometer and FBG.

\section{Experiments and Results}

The experimental test system was set up with computer, spectrum analyzer, pressure tank, temperature control cabinet and gas cylinder, as shown in Figure 6. The light beam propagates from the spectrum analyzer (SM125, Micron Optics Inc., Atlanta, GA, USA), and it transmits into the sensor proposed in this paper for pressure and temperature detection. The sensor was placed into the pressure tank for the pressure tests at different stable temperatures. The temperature produced by the heater was controlled with the temperature control cabinet, and the pressure was adjusted by the gas cylinder. The temperature and pressure in the tank were measured by a calibrated temperature sensor and a calibrated pressure sensor which the accuracy were $\pm 0.1 \%$ F.S and $\pm 5 \%$ MPa respectively. The data recorded by the spectrum analyzer with a resolution of $1 \mathrm{pm}$ under the range of $1510 \mathrm{~nm}$ to $1590 \mathrm{~nm}$ is processed with the PC.

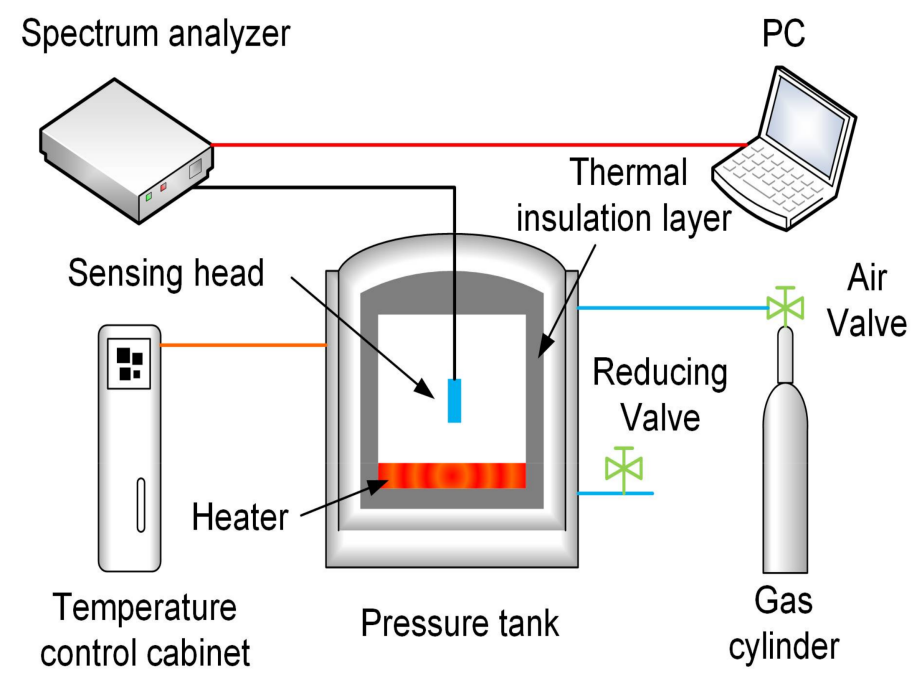

Figure 6. Experimental setup for pressure and high-temperature test. 
The calibration process of the sensor in the nitrogen environment is as follows. Put the sensor in the tank and get as close to the heater as possible to detect the operating temperature, the pressure in the tank was changed by filling the tank with the pure nitrogen. Adjust the pressure in the tank from approximately $0.1 \mathrm{MPa}$ (barometric pressure) to $0.7 \mathrm{MPa}$ at 20, 200, 400, 600 and $800^{\circ} \mathrm{C}$. At each $0.1 \mathrm{Mpa}$, recorded the interference spectrum after maintaining the temperature for $5 \mathrm{~min}$. The experimental results show that the interference spectrum shifts to a long wavelength consistently as the pressure increases at $20,200,400,600$ and $800^{\circ} \mathrm{C}$. Figure 6 a shows the spectrum shift at the pressure of $0.1,0.4$ and $0.7 \mathrm{MPa}$ under $20^{\circ} \mathrm{C}$. Figure $7 \mathrm{a}$ is the shift of the spectrum when the pressure stabilized at $0.1,0.4$ and $0.7 \mathrm{MPa}$ at $20^{\circ} \mathrm{C}$. From Figure $7 \mathrm{a}$, it can be seen that the sensor has a sensitive response to the pressure. Due to the temperature being maintained at $20^{\circ} \mathrm{C}$, the center wavelength of the FBG has no shift. The pressure monitoring point and temperature monitoring point are shown in Figure $6 \mathrm{a}$. The initial FPI "peak" and center wavelength of the FBG are $\lambda_{0}=1563.0524$ and $\lambda_{F B G}=1574.8658 \mathrm{~nm}$, respectively. The fitting curves of the wavelength at different pressures under 20, 200, 400, 600 and $800{ }^{\circ} \mathrm{C}$ are shown in Figure $7 \mathrm{~b}$. From Figure $7 \mathrm{~b}$, it can be seen that the wavelength has a good linear relationship with the pressure, and duplicate experimental results are in a good agreement. This proves that the sensor has a good linearity and repeatability at different temperatures. The sensitivities at 20 , $200,400,600$ and $800{ }^{\circ} \mathrm{C}$ are $4.28,2.62,1.83,1.41$ and $1.15 \mathrm{~nm} / \mathrm{MPa}$, respectively.

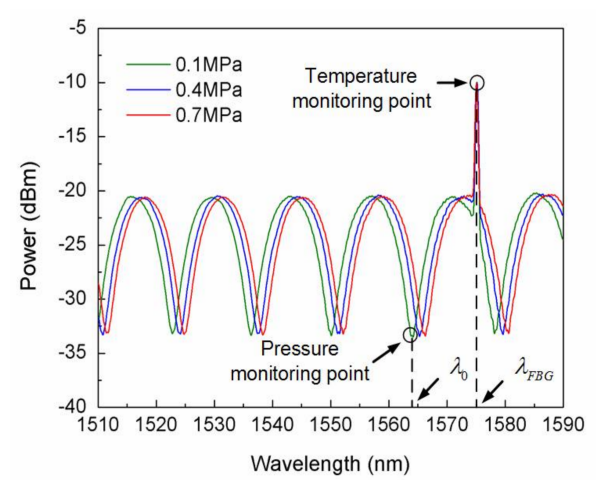

(a)

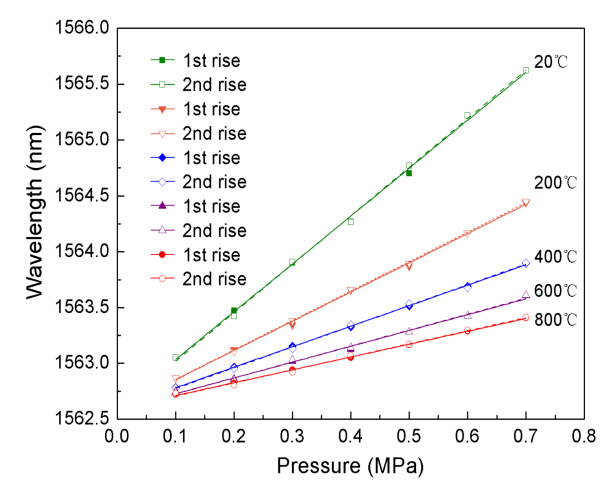

(b)

Figure 7. Interference spectrum: (a) FP interferometer with stable FBG; (b) The shifts of wavelength with pressure at $20,200,400,600$ and $800{ }^{\circ} \mathrm{C}$.

The stability of the sensor proposed in the paper was measured under pressure at 0.1, 0.4 and $0.7 \mathrm{MPa}$ at $800{ }^{\circ} \mathrm{C}$ for about $100 \mathrm{~min}$, the results is shown in Figure 8, where it can be seen that the sensor proposed in the paper had good stability with slight variations in the wavelength response for at least $100 \mathrm{~min}$.

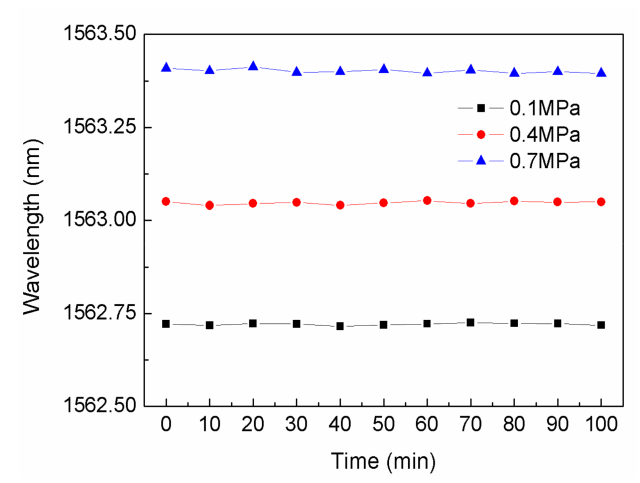

Figure 8. The stability test results of the proposed sensor at $0.1,0.4$ and $0.7 \mathrm{MPa}$ under $800{ }^{\circ} \mathrm{C}$ for $100 \mathrm{~min}$. 
The FBG used in the sensor has been annealed and reached a stabilization point. The relationship between the FBG center wavelength and temperature is shown in Figure 9a. It can be seen that the FBG center wavelength has a good linear relationship with the temperature and shifts to a long wavelength as the temperature rises from 20 to $800{ }^{\circ} \mathrm{C}$. The FBG center wavelength can be fitted with the relationship of the Equation (5) with $\mathrm{A}=1574.7756, \mathrm{~B}=0.0125, \mathrm{C}=3.8889 \times 10^{-6}$ and $\mathrm{D}=-1.6458 \times 10^{-9}$, where $\lambda_{F B G}$ is the FBG central wavelength. The fitting degree is $99.98 \%$. From Figure 7b, the relationship between the wavelength and pressure at 20, 200, 400, 600 and $800{ }^{\circ} \mathrm{C}$ can be obtained by the wavelength at $0.1 \mathrm{MPa}$ and the sensitivity at the corresponding temperature. The wavelength of pressure monitoring point at 20,200, 400, 600 and $800{ }^{\circ} \mathrm{C}$ under $0 \mathrm{MPa}$, calculated by the relationship between the wavelength and pressure, are 1562.6064, 1562.5912, $1562.5987,1562.5856$ and $1562.5966 \mathrm{~nm}$, respectively. The wavelength has almost no drift proving the temperature compensation structure is effective. The average of the wavelength is $1562.5957 \mathrm{~nm}$. From Figure $7 \mathrm{~b}$, we can fit the wavelength values corresponding to the pressure monitoring point at each step from 0.1 Mpa to 0.7 Mpa to get the sensitivities of the sensor at 20, 200, 400, 600 and $800{ }^{\circ} \mathrm{C}$. The sensitivities of the sensor at different temperatures are fitted with the relationship of Equation (6) with $a=1.5087, b=-0.0029$ and $c=1.5703 \times 10^{-6}$. The fitting of the sensitivities is shown in Figure $9 \mathrm{~b}$. In Figure $9 b$, it can be seen that the sensitivities have an exponential relationship with the temperature and the fitting degree is $99.74 \%$.

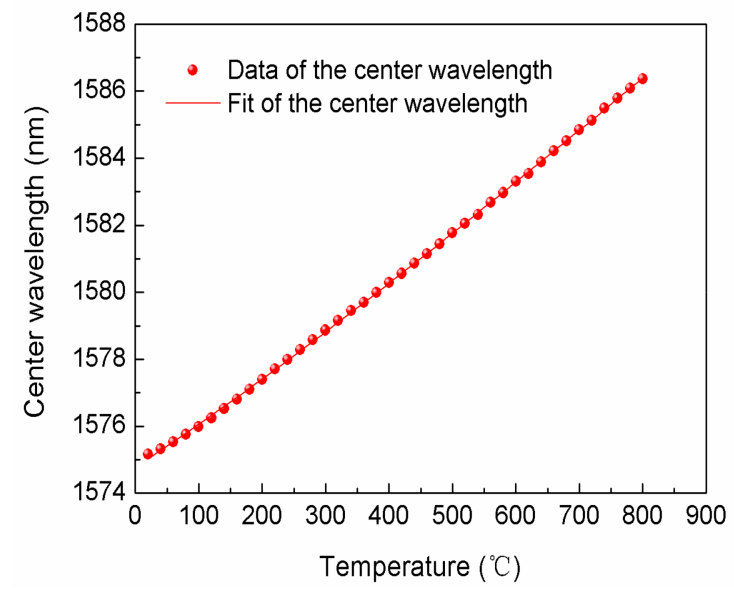

(a)

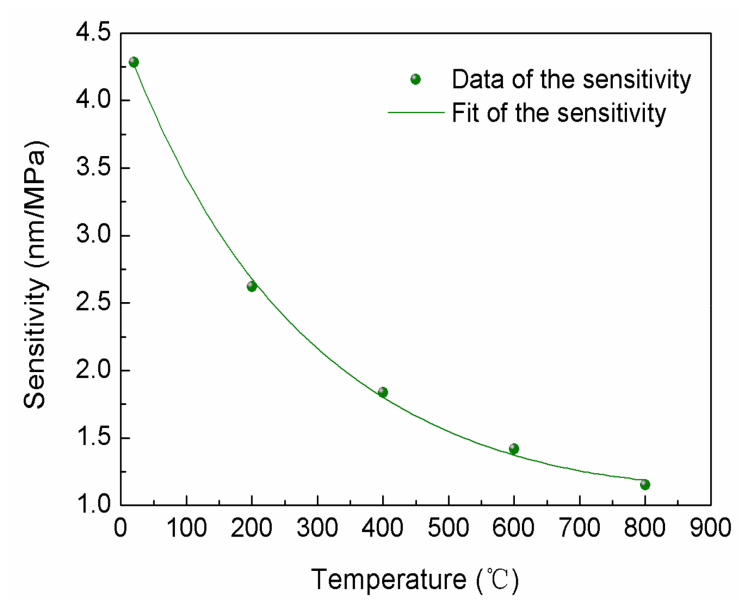

(b)

Figure 9. Fitting curves of the relationship of: (a) FBG center wavelength and temperature; (b) sensitivity and temperature.

$$
\begin{gathered}
\lambda_{F B G}=A+B \cdot T+C \cdot T^{2}+D \cdot T^{3} \\
y=e^{a+b \cdot T+c \cdot T^{2}},
\end{gathered}
$$

By using the temperature decoupling method, the calculated values and the fitting curves of the calculated values at 20, 400 and $800{ }^{\circ} \mathrm{C}$ are respectively shown in Figure 10a-c. In Figure 10, the pressures measured by the pressure gauge of the high-temperature pressure compounding platform are the actual values. From Figure 10, it can be seen that the calculated values are in good agreement with the actual values, and there is only a slight error between the calculated values and the actual values. The slopes of the fitting curves of the calculated values at 20,400 and $800{ }^{\circ} \mathrm{C}$ are $1.00071,0.9887$ and 0.99497 , respectively, which are very close to 1 . This proves that the presented sensor is quite reliable. The maximum error of the calculated values at 20,400 and $800{ }^{\circ} \mathrm{C}$ are $5.3,7.6$ and $8.1 \mathrm{KPa}$ respectively. The non-linearity errors of the calculated values are $0.88 \%, 1.28 \%$ and $1.34 \%$, respectively, which is less than that of the conventional gas pressure sensors on the market. The reason why the deviation of the calculated values from the actual value increases with the temperature increases may 
be due to the deviation of the sensitivity fitting increases as the temperature increases. In the future work, we will conduct a better study of the fitting method. We believe it will be better to improve the accuracy of the temperature decoupling method.

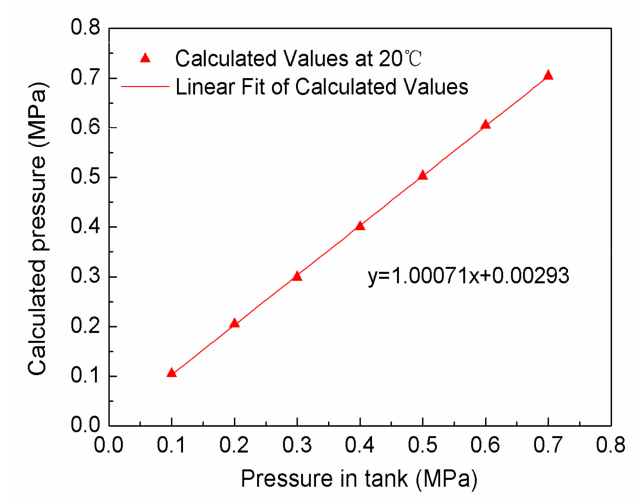

(a)

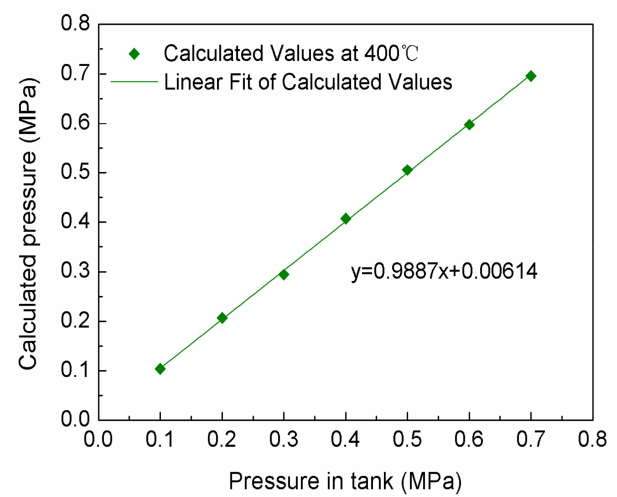

(b)

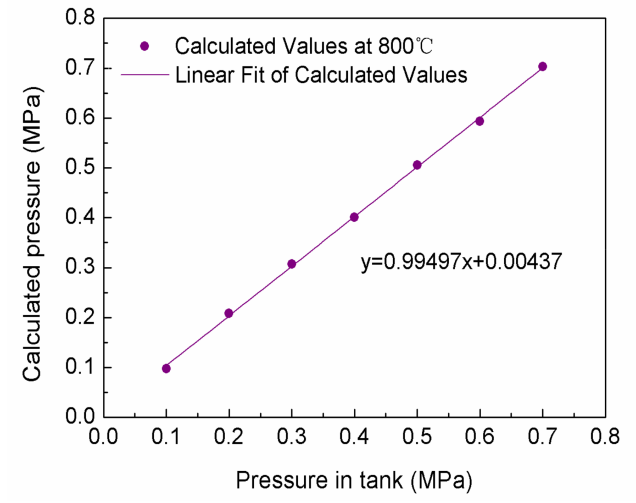

(c)

Figure 10. Temperature decoupling results: (a) at $20^{\circ} \mathrm{C}$; (b) at $400^{\circ} \mathrm{C}$; (c) at $800^{\circ} \mathrm{C}$.

Because the pressure measurement results are related to the refractive index of the gas, the sensor can be used for single-component gas or mixed-component invariant gas detection applications, such as, pressure monitoring of high-temperature steam in the pipelines of a thermal power station, and pressure measurements under laboratory conditions. In summary, the sensor can be used in the monitoring the single-component or mixed-component invariant gas environments by calibrating the sensor according to the environment used. If the gas mixture composition changes during the measurement, the sensor would not suitable for such an environment, unless we realize the situation after the change.

\section{Conclusions}

To summarize, a diaphragm-free fiber-optic gas pressure sensor for high temperature environments based on pressure changes with gas density, which provides a method of pressure measurement at high temperature is presented. It uses a FBG to realize the in-situ temperature measurement. The pressure sensitivity of the fiber-optic FP gas pressure sensor is $4.28 \mathrm{~nm} / \mathrm{MPa}$ with a high linear pressure response over the range of 0.1-0.7 MPa and the temperature sensitivity is $14.8 \mathrm{pm} /{ }^{\circ} \mathrm{C}$ within the $20-800{ }^{\circ} \mathrm{C}$ range. The sensor has less than $1.5 \%$ non-linearity at different temperatures by using a temperature decoupling method. The sensor has advantages of extremely low temperature coefficient, compact structure, small size, simple production and low cost which will help the sensor offer the excellent features required for pressure measurements in high temperature applications. 
Acknowledgments: This work was supported by the National Science Fund for Distinguished Young Scholars under Grant 51425505, the National Natural Science Foundation of China under Grant 51405454, and Fund for Shanxi "1331 Project" Key Subject Construction.

Author Contributions: The work presented in this paper was a collaboration of all authors. Hao Liang, Pinggang Jia and Jijun Xiong designed Diaphragm-free fiber-optic Fabry-Perot interferometric gas pressure sensor; Hao Liang, Yingping Hong and Ting Liang conceived and designed the experiments; Hao Liang and Jia Liu performed the experiments; Hao Liang and Guocheng Fang analyzed the data; Hao Liang wrote the paper, which was discussed and revised by all authors.

Conflicts of Interest: The authors declare no conflict of interest.

\section{References}

1. Jewart, C.M.; Wang, Q.Q.; Canning, J.; Grobnic, D.; Mihailov, S.J.; Chen, K.P. Ultrafast femtosecond-laser-induced fiber Bragg gratings in air-hole microstructured fibers for high-temperature pressure sensing. Opt. Lett. 2010, 35, 1443-1445. [CrossRef] [PubMed]

2. Sohail, M.A.; Mustafa, A.I. A study on damages in alloyed super heater tubes of thermal power station. Indian J. Eng. Mater. Sci. 2007, 14, 19-23.

3. Rao, Y.J.; Zhu, T.; Yang, X.C.; Duan, D.W. In-line fiber-optic etalon formed by hollow-core photonic crystal fiber. Opt. Lett. 2007, 32, 2662-2664. [CrossRef] [PubMed]

4. Zhu, T.; Wu, D.; Liu, M.; Duan, D.W. In-Line Fiber Optic Interferometric Sensors in Single-Mode Fibers. Sensors 2012, 12, 10430-10449. [CrossRef] [PubMed]

5. Ma, Z.M.; Huang, Y.W.; Meng, H.Y.; Huang, X.G. Simultaneous Measurement of Temperature and Pressure by Utilizing an Integrated Mach-Zehnder. J. Lightwave Technol. 2017, 35, 4924-4929. [CrossRef]

6. Peng, F.; Yang, J.; Li, X.L.; Yuan, Y.G.; Wu, B.; Zhou, A.; Yuan, L.B. In-fiber integrated accelerometer. Opt. Lett. 2011, 36, 2056-2058. [CrossRef] [PubMed]

7. Byeong, H.L.; Young, H.K.; Kwan, S.P.; Joo, B.E.; Myoung, J.K.; Byung, S.R.; Hae, Y.C. Interferometric Fiber Optic Sensors. Sensors 2012, 12, 2467-2486. [CrossRef]

8. Donlagic, D.; Cibula, E. All-fiber high-sensitivity pressure sensor with $\mathrm{SiO}_{2}$ diaphragm. Opt. Lett. 2005, 30, 2071-2073. [CrossRef] [PubMed]

9. Melissinaki, V.; Farsari, M.; Pissadakis, S. A Fiber-Endface, Fabry-Perot Vapor Microsensor Fabricated by Multiphoton Polymerization. IEEE J. Sel. Top. Quantum Electron. 2015, 21, 5600110. [CrossRef]

10. Poeggel, S.; Tosi, D.; Leen, G.; Lewis, E. Low-cost miniature fiber-optic extrinsic Fabry-Perot interferometric pressure sensor for biomedical applications. In Proceedings of the SPIE-Advanced Microscopy Techniques III, Munich, Germany, 17 June 2013.

11. Wang, Q.; Zhang, L.; Sun, C.S.; Yu, Q.X. Multiplexed Fiber-Optic Pressure and Temperature Sensor System for Down-Hole Measurement. IEEE Sens. J. 2008, 8, 1879-1883. [CrossRef]

12. Duraibabu, D.B.; Poeggel, S.; Omerdic, E.; Kalli, K.; Capocci, R.; Lacraz, A.; Dooly, G.; Lewis, E.; Newe, T.; Leen, G.; et al. Novel miniature pressure and temperature optical fibre sensor based on an extrinsic Fabry-Perot Interferometer (EFPI) and Fibre Bragg Gratings (FBG) for the Ocean environment. Proc. IEEE Sens. 2014, 2014, 394-397. [CrossRef]

13. Villatoro, J.; Kreuzer, M.P.; Jha, R.; Minkovich, V.P.; Finazzi, V.; Badenes, G.; Pruneri, V. Photonic crystal fiber interferometer for chemical vapor detection with high sensitivity. Opt. Express 2009, 17, 1447-1453. [CrossRef] [PubMed]

14. Ran, Z.L.; Liu, S.; Liu, Q.; Wang, Y.J.; Bao, H.H.; Rao, Y.J. Novel High-Temperature Fiber-Optic Pressure Sensor Based on Etchd PCF F-P Interferometer Micromachined by a 157-nm Laser. IEEE Sens. J. 2015, 15, 3955-3958. [CrossRef]

15. Ferreira, M.S.; Bierlich, J.; Lehmann, H.; Schuster, K.; Kobelke, J.; Santos, J.L.; Frazao, O. Fabry-Perot Cavity Based on Hollow-Core Ring Photonic Crystal Fiber for Pressure Sensing. IEEE Photonics Technol. Lett. 2012, 24, 2122-2124. [CrossRef]

16. Xu, B.; Wang, C.; Wang, D.N.; Liu, Y.M.; Li, Y. Fiber-tip gas pressure sensor based on dual capillaries. Opt. Express 2015, 23, 23484-23492. [CrossRef] [PubMed]

17. Zhang, C.Z.; Yang, Y.H.; Wang, C.; Liao, C.R.; Wang, Y.P. Femtosecond-laser-inscribed sampled fiber Bragg grating with ultrahigh thermal stability. Opt. Express 2016, 24, 3981-3988. [CrossRef] [PubMed] 
18. Xia, J.; Wang, F.Y.; Luo, H.; Wang, Q.; Xiong, S.D. A Magnetic Field Sensor Based on a Magnetic Fluid-Filled FP-FBG Structure. Sensors 2016, 16, 620. [CrossRef] [PubMed]

19. Jia, P.G.; Fang, G.C.; Liang, T.; Hong, Y.P.; Tan, Q.L.; Chen, X.Y.; Liu, W.Y.; Xue, C.Y.; Liu, J.; Zhang, W.D.; et al. Temperature-compensated fiber-optic Fabry-Perot interferometric gas refractive-index sensor based on hollow silica tube for high-temperature application. Sens. Actuators B Chem. 2017, 244, 226-232. [CrossRef]

(C) 2018 by the authors. Licensee MDPI, Basel, Switzerland. This article is an open access article distributed under the terms and conditions of the Creative Commons Attribution (CC BY) license (http:/ / creativecommons.org/licenses/by/4.0/). 